\title{
A High efficiency and High power density Asymmetrical Half-bridge Flyback Converter for Data Centers
}

\section{Li, Mingxiao; Ouyang, Ziwei; Andersen, Michael A. E.}

\section{Published in:}

Proceedings of IEEE $47<$ sup $>$ th $</$ sup $>$ Annual Conference of IEEE Industrial Electronics

Link to article, DOI:

10.1109/IECON48115.2021.9589575

Publication date:

2021

Document Version

Peer reviewed version

Link back to DTU Orbit

Citation (APA):

Li, M., Ouyang, Z., \& Andersen, M. A. E. (2021). A High efficiency and Hhigh power density Asymmetrical Halfbridge Flyback Converter for Data Centers. In Proceedings of IEEE 47 Annual Conference of IEEE Industrial Electronics IEEE. https://doi.org/10.1109/IECON48115.2021.9589575

\section{General rights}

Copyright and moral rights for the publications made accessible in the public portal are retained by the authors and/or other copyright owners and it is a condition of accessing publications that users recognise and abide by the legal requirements associated with these rights.

- Users may download and print one copy of any publication from the public portal for the purpose of private study or research.

- You may not further distribute the material or use it for any profit-making activity or commercial gain

- You may freely distribute the URL identifying the publication in the public portal 


\title{
A High efficiency and High power density Asymmetrical Half-bridge Flyback Converter for Data Centers
}

\author{
Mingxiao Li, Student Member, IEEE, Ziwei Ouyang, Senior Member, IEEE and Michael A. E. Andersen, Member IEEE
}

Deparment of Electrical Engineering, Techical University of Denmark, Copenhagen, Denmark, zo@elektro.dtu.dk

\begin{abstract}
The power consumption in data centers continues increasing, thereby pushing the converter to achieve high efficiency and high power density. This paper presents an asymmetrical half-bridge flyback converter for data center applications. Compared with an active clamp flyback converter, it functions as an isolated buck converter, and is more preferable for voltage step-down applications. The operating principle and the design considerations are included in this paper. An interleaving winding layout with uniformed current distributions is used for the planar transformer design. The built prototype satisfies an industrial standard low-profile sixteenth brick requirement, and achieves $94.9 \%$ peak efficiency and $468 \mathrm{~W} / \mathrm{inch}^{3}$ power density.
\end{abstract}

Keywords-asymmetrical half-bridge flyback converter, active clamp flyback converter, planar transformer

\section{INTRODUCTION}

The ever-growing demand for cloud computing and data processing has consumed significant electric power in 2020 , and is expected to continue increasing in the coming future, thereby pushing power converters to be more efficient and compact. The $48 \mathrm{~V}$ bus distribution system proposed by Google has been gradually adopted to replace the conventional $12 \mathrm{~V}$ bus. This architecture improves the system efficiency. However, it also poses a challenge to converters' design.

The standard brick size is normally required in the industry. Conventional two-stage structures or converters with multi-stages are proposed and analyzed in many excellent papers. It is known to all that the efficiency of the two-stage converter is the product of the front stage and second stage, which also poses a penalty on system efficiency [1]-[3]. Converters with multi-stages have more functions than singlestage converters. Literature [4] proposes a sigma converter to transfer the majority of the input power through the LLC resonant converter as a DC transformer, while a small portion of power is regulated by the PWM converter to regulate the output. It improves the system efficiency by using the concept of partial power regulation. Another architecture with the functionality of the partial power regulation is proposed in [5]. Two LLCs are integrated into one magnetic core to improve the power density. However, these structures require many power devices or magnetic components, which are hard to realize the power density requirement.

This brings one to re-investigate the single-stage solutions. Switch-capacitor converters [6]-[8] are capable to achieve a significantly high efficiency within a tiny volume. However, gate driver circuits tend to be more complex when there are more power stages. Additionally, these converters are hard to regulate the output voltage and not isolated. A single LLC resonant converter with regulation capability demands a large resonant inductor, which increases the system volume. When the switching frequency swings away from the resonant frequency, the power losses greatly increase due to the circulating energy [9]-[11]. Conventional half-bridge converters and forward converters are usually used to achieve both the efficiency and the power density requirements.

This paper looks into the asymmetrical half-bridge(AHB) flyback converter. It functions as an isolated buck converter and is therefore preferable for voltage-step down applications. The operating principles and design considerations are presented in this paper. A larger resonant capacitor can reduce the primary and secondary RMS current, but increase the turnoff losses. Due to the high current at the secondary side, parallel conductors are used to share the high current. However, the current distributions are usually unbalanced. Three 4:1 interleaving winding layouts with primary conductors in series and secondary conductors in parallel are compared. The winding layout which has the minimum AC resistance is selected. Ansys 2D simulation shows that this winding layout has uniformly distributed current on parallel conductors. The built prototype shows better performance than the state-of-the-art. It achieves $94.9 \%$ peak efficiency and $468 \mathrm{~W} /$ inch $^{3}$ power density.

The remainder of this paper is organized as follows: Section II presents the operating principles of the AHB flyback converter. Subsequently, design considerations are given in Section III. Section IV shows the experiment results. Section V concludes this paper.

\section{OPERATING PRINCIPEL OF THE ASYMMETRICAL HALF- BRIDGE FLYBACK CONVERTER}

Compared with an active clamp flyback (ACF) converter, the asymmetrical half-bridge (AHB) flyback converter is more preferable for voltage step-down applications. Two configurations of the AHB flyback converter are presented in Fig.1. TABLE I summarizes the voltage stress comparison between these two converters. All active components of the AHB flyback converter have smaller voltage stress compared with the ACF converter. Furthermore, from the voltage transfer ratio of $V_{o} / V_{i n}$, the AHB flyback converter can be regarded as an isolated buck converter, while the ACF converter is an isolated buck-boost converter. Therefore, the former is more suitable for voltage step-down applications. 


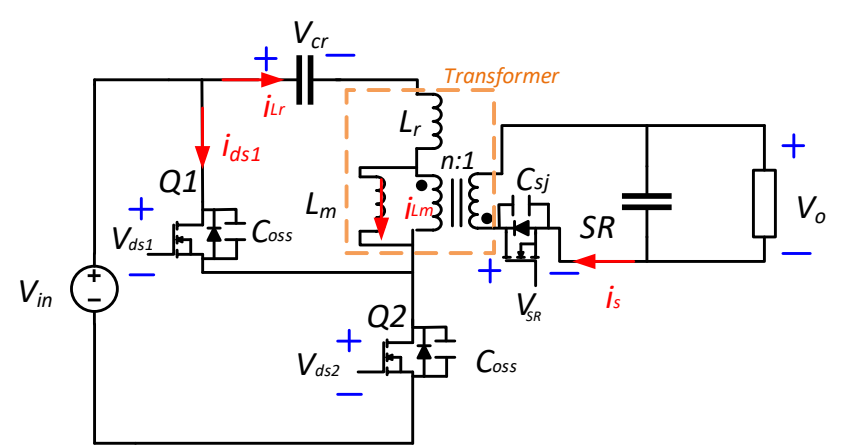

(a)

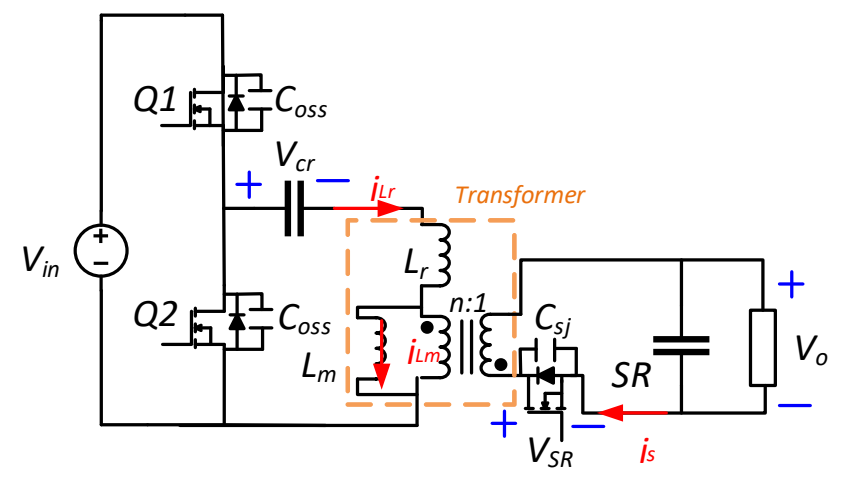

(b)

Fig.1. Two configurations of the AHB flyback converter

TABLE I

COMPARISON BETWEEN TRADITIONAL ACF AND AHB FLYBACK

\begin{tabular}{lccc}
\hline \hline & $V_{d s l}$ or $V_{d s 2}$ & $V_{d}$ & $V_{o} / V_{i n}$ \\
\hline ACF & $V_{i n}+n V_{o}$ & $V_{i n} / n+V_{o}$ & $D / n(1-D)$ \\
AHB flyback & $V_{i n}$ & $V_{i n} / n$ & $D / n$ \\
\hline \hline
\end{tabular}

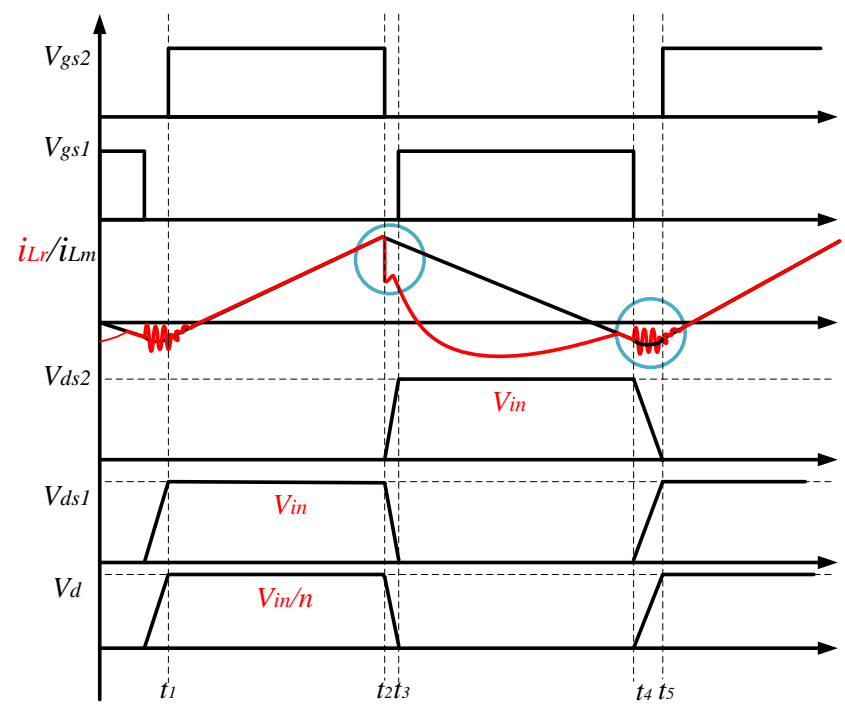

Fig.2. Operating waveforms of the circuit shown in Fig.1(a)

The operating principles of these two configurations are identical. Only the configuration shown in Fig.1(a) is analyzed. Fig. 2 presents the main current and voltage waveforms of the circuit shown in Fig.1(a). The steady-state operating principles are given as follows:
Stage $1\left(t_{0}<t<t_{1}\right)$ : At $t_{0}$, switch $Q_{2}$ turns on, and switch $Q_{1}$ is clamped by the input voltage $V_{i n}$. The magnetizing current $i_{L m}$ and the resonant current $i_{L r}$ are increasing linearly and follow:

$$
i_{L m}(t)=i_{L r}(t)=i_{L r}\left(t_{1}\right)+\frac{V_{i n}-V_{C r}}{L_{r}+L_{m}} t
$$

where $L_{r}$ is the resonant inductor and $L_{m}$ is the magnetizing inductor.

In this time interval, the secondary rectifier $S R$ is blocked and the energy is stored in the transformer (or coupled inductor). The voltage applied to the primary winding $V_{p}$ is

$$
V_{p}=\frac{V_{i n}-V_{C r}}{L_{r}+L_{m}} L_{m}
$$

Stage $2\left(t_{2}<t<t_{3}\right)$ : There is a current dip on the resonant current during this ZVS transition where switch $Q_{2}$ is off. This phenomenon has been analyzed in [12], which is primarily due to the current shared by the primary and secondary parasitic capacitances, $C_{o s s}$ and $C_{s j}$. In this time interval, the resonant current discharges the output capacitance of switch $Q_{1}$ and charges the output capacitance of switch $Q_{2}$. $S R$ is also discharging by the secondary current. This stage ends when switch $Q_{1}$ is fully discharged by the resonant current.

Stage $3\left(t_{3}<t<t_{4}\right)$ : Switch $Q_{1}$ achieves the ZVS turn on at $t_{3}$. Secondary rectifier $S R$ starts to conduct. The resonant capacitor $C_{r}$ and the resonant inductor $L_{r}$ join in the resonance. The resonant current $i_{L r}$ satisfies:

$$
i_{L r}(t)=i_{L r}\left(t_{3}\right) \cos \left(w_{r} t\right)+\frac{\left(n V_{o}-V_{C r}\left(t_{3}\right)\right)}{Z_{r}} \sin \left(w_{r} t\right)
$$

where

$$
w_{r}=1 / \sqrt{L_{r} C_{r}}, Z_{r}=\sqrt{\frac{L_{r}}{C_{r}}}
$$

The voltage applied to the primary winding $V_{p}$ is

$$
V_{p}=-\frac{V_{C r}}{L_{r}+L_{m}} L_{m}
$$

Assume $L_{r}<<L_{m}$. The magnetizing inductor follows the voltage-second-balance, which is given by

$$
D\left(V_{i n}-V_{C r}\right)=V_{C r}(1-D)
$$

where $D$ is the duty cycle of the switch $Q_{2} . V_{c r}$ is the average voltage on the resonant capacitor. It can be solved by

$$
V_{C r}=V_{\text {in }} D
$$

This time interval ends when switch $Q_{l}$ turns off.

Stage $4\left(t_{4}<t<t_{5}\right)$ : The current dip also occurs in this ZVS transition. Detailed analysis can be found in [12]. The resonant current discharges switch $Q_{2}$ and charges switch $Q_{1}$. SR is charging by the secondary current.

\section{CONVERTER DESIGN}


The design specification is presented in TABLE I. The input voltage changes from $32 \sim 75 \mathrm{~V}$ and the nominal input is $48 \mathrm{~V}$. The leakage inductance of the transformer is utilized as the resonant inductance. The leakage inductance usually has limited energy to realize the ZVS for all devices. The converter is therefore designed to operate at discontinues conduction mode (DCM). The magnetizing current $i_{L m}$ joins in the charge and the discharge of the parasitic capacitances of all active devices. In this section, the design of circuit parameters for the AHB flyback converter will be introduced.

TABLE I

DESIGN SPECIFICATION

\begin{tabular}{ccc}
\hline \hline Symbol & Quantity & Value \\
\hline$V_{\text {in }}$ & Input voltage & $32 \sim 75 \mathrm{~V}$ \\
& Nominal input & $48 \mathrm{~V}$ \\
$V_{o}$ & Output voltage & $5 \mathrm{~V}$ \\
$P_{o}$ & Output power & $100 \mathrm{~W}$ \\
\hline \hline
\end{tabular}

\section{A. Transformer}

Similar with an active clamp flyback converter, the AHB flyback converter can achieve higher efficiency with an interleaving winding layout. Fig.3 presents the current waveforms in the transformer, resonant current $i_{L r}$, magnetizing current $i_{L m}$, and secondary winding current $i_{s}$. It can be observed that there is negative conduction of the resonant current. This phenomenon can be explained by the current-second balance of the resonant capacitor $C_{r}$. The shaded area II is identical with the other shaded area I. The negative resonant current helps reduce the proximity effect, because $i_{L r}$ and $i_{s}$ are in the opposite directions. The AC resistance can be therefore reduced by employing the interleaved winding layout.

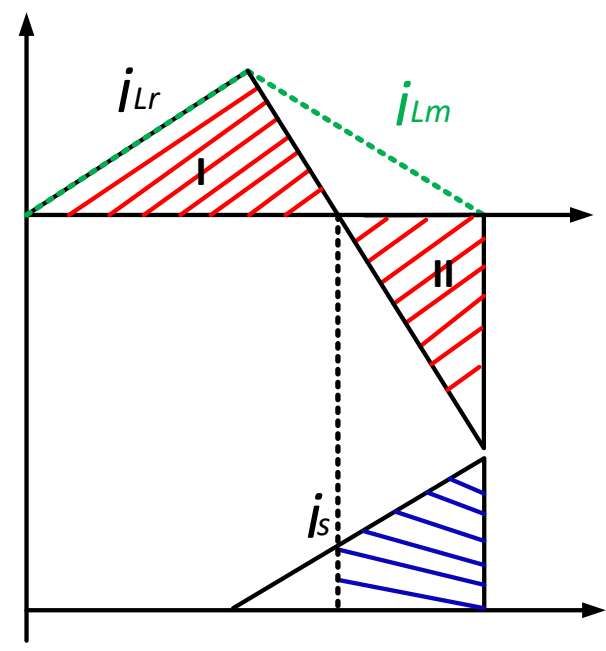

This design deals with a high current at the secondary side. Parallel connections are necessary for secondary windings to share the high current. Three interleaving winding layouts with secondary conductors connected in parallel, shown in Fig.4, are analyzed and compared. TABLE II documents winding details. They are 4:1 planar windings with primary conductors in series and secondary conductors in parallel. The insulation thickness is assumed to be identical for each layer. AC resistances of these three cases simulated by Ansys 2D are presented in Fig.5. Case I and Case III cross each other at $830 \mathrm{kHz}$. Case III has the smallest AC resistance when the frequency is below the crossing point, while Case I shows the minimum $\mathrm{AC}$ resistance when the frequency is higher than the crossing point. From this comparison, depending on the frequency, the optimal winding layouts can be selected accordingly.

TABLE II

WINDING DETAILES

\begin{tabular}{lc}
\hline \hline Parameters & Values \\
\hline Copper thickness $(h)$ & $70 \mu \mathrm{m}$ \\
Turn ratio $(n: 1)$ & $4: 1$ \\
Insulation thickness $(t)$ & $0.3 \mathrm{~mm}$ \\
Window width $(b)$ & $5 \mathrm{~mm}$ \\
Resistivity $(\rho)$ & $1.71 \times 10^{-8} \Omega \cdot \mathrm{m}$ \\
Air permeability $\left(\mu_{o}\right)$ & $4 \pi \times 10^{-7} \mathrm{H} / \mathrm{m}$ \\
Magnetic core & $\mathrm{E} 18 / 4 / 10$ \\
Relative permeability of th & 900 \\
e core $\left(\mu_{c}\right)$ & \\
\hline \hline
\end{tabular}

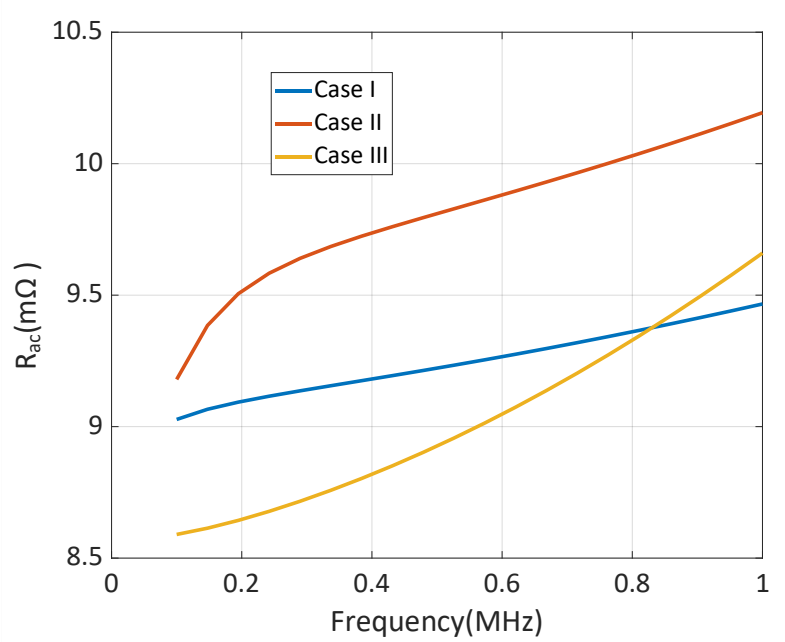

Fig.5. AC resistances of three winding layouts as functions of frequency

Fig.3. Currents waveforms in the transformer

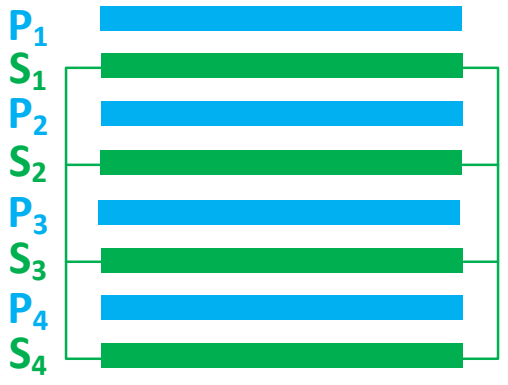

(a) Case I

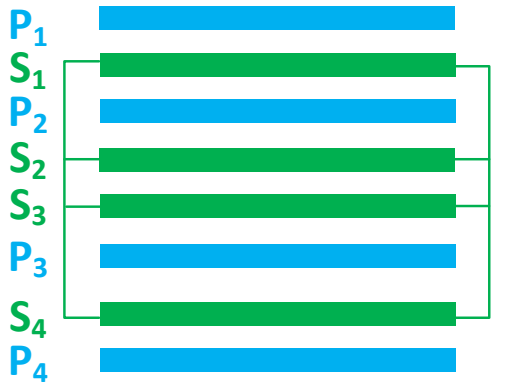

(b) Case II

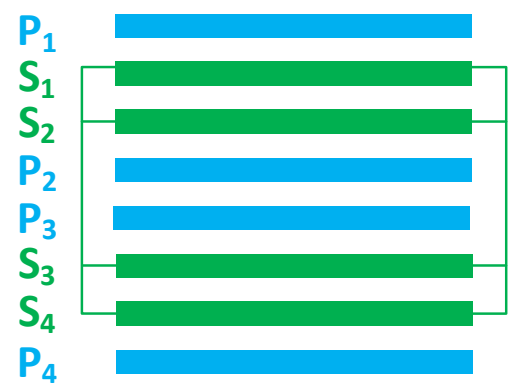

(c) Case III

Fig.4 Three winding parallel schemes of a turn ratio 4:1 planar windings with primary series connected and secondary layers parallel connected 


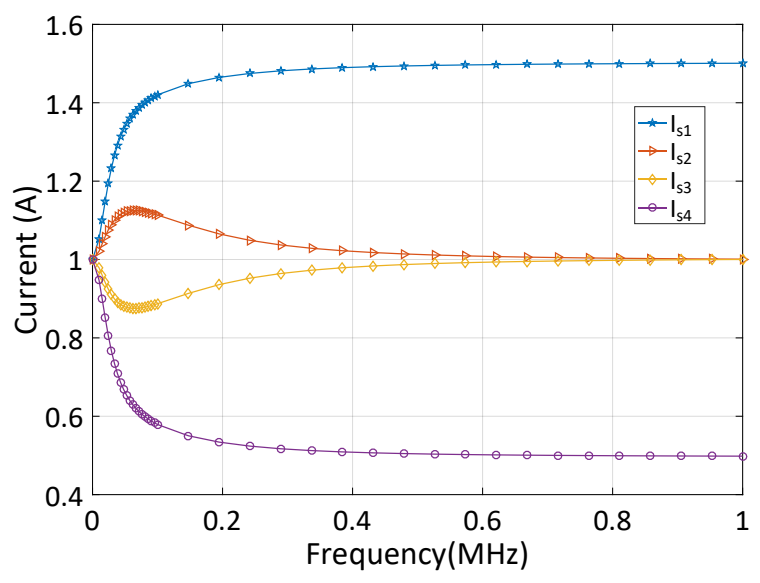

(a)

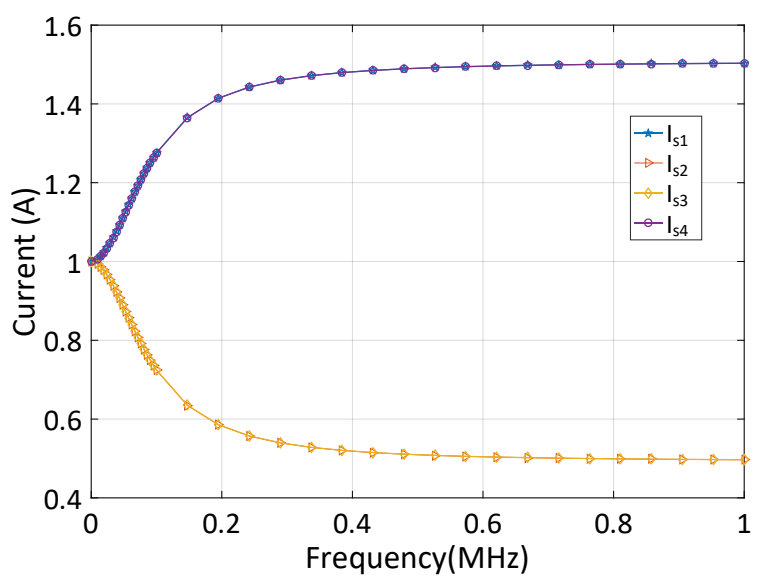

(b)

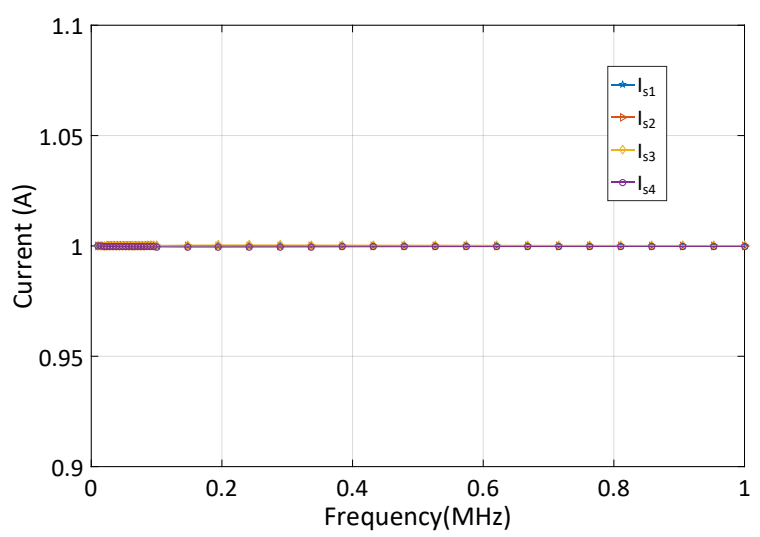

(c)

Fig.6. Secondary peak current on each conductor for (a) Case I, (b) Case II and (c) Case III. The frequency sweeps from $10 \mathrm{kHz}$ to $1 \mathrm{MHz}$.

Current distributions of secondary conductors are analyzed by Ansys 2D. Each primary conductor is excited by 1A peak sinusoidal current. The secondary peak current on each conductor is measured and shown in Fig.6. It can be seen that each conductor in Case III has the same current across the whole swept frequency from $10 \mathrm{kHz}$ to $1 \mathrm{MHz}$. This winding layout has uniformly distributed current, which the others have unbalanced current distributions. In this design, the switching frequency is below $830 \mathrm{kHz}$. The winding layout shown in Case III is therefore selected for the transformer design.

\section{B. Magnetizing inductance}

To realize the ZVS for all active devices, the magnetizing inductance should be carefully designed. According to the charge balance during the ZVS transition, it satisfies

$$
I_{\text {Lm_min }} t_{d}=2 C_{\text {oss }} V_{\text {in }}+C_{p s} V_{\text {in }}
$$

Where $I_{L m \_m i n}$ is the minimum magnetizing current. It is given by

$$
\begin{gathered}
I_{L m_{-} \min }=I_{L m_{-} a v g}-\frac{n V_{o}(1-D)\left(T_{s}-t_{d}\right)}{2 L_{m}} \\
I_{L m_{-} a v g}=I_{L r_{-} a v g}+I_{s_{-} a v g}=\frac{I_{o}}{n}
\end{gathered}
$$

$I_{L m \_a v g}$ is the average current of the magnetizing current. It is the sum of the $I_{L r_{-} a v g}$ and $I_{S_{-} a v g}$, which are the average $i_{L r}$ and $i_{s}$, respectively. The average $i_{L r}$ is zero because of the currentsecond balance of $C_{r}$. $I_{L m \_a v g}$ is therefore equivalent to the referred secondary average current $I_{s_{-} \text {avg }}$. Combining (7), (8), and (9), the magnetizing inductance $L_{m}$ can be solved by

$$
L_{m}=\frac{n^{2} V_{o}(1-D)\left(T_{s}-t_{d}\right) t_{d}}{\left(4 n C_{o s s}+2 C_{p s}\right) V_{i n}+2 I_{o} t_{d}}
$$

\section{Resonant capacitor}

From Fig.7, a smaller resonant capacitor shows almost zero turn-off current for switch $Q_{l}$ and secondary rectifier $S R$, while a larger resonant capacitor presents a higher turn-off current. However, a larger resonant capacitor yields smaller primary and secondary RMS current, but higher turn-off loss, as presented in Fig.8. Thus, a trade-off has to be made between the turn-off loss and conduction loss. In this design, the AHB flyback converter is dealing with high current for both primary and secondary sides, where conduction power loss dominates. A larger resonant capacitor is therefore more preferable to reduce the conduction loss.

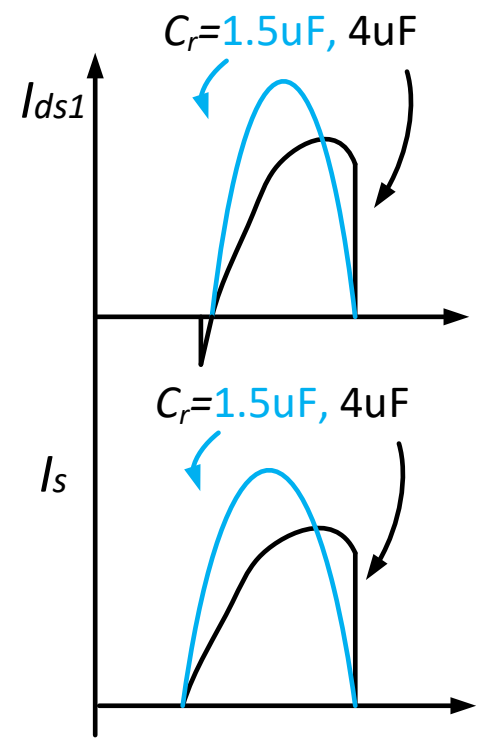

Fig.7. Current waveforms at different resonant capacitors. The switching frequency is $290 \mathrm{kHz}$, and the resonant inductance is $53 \mathrm{nH}$ 


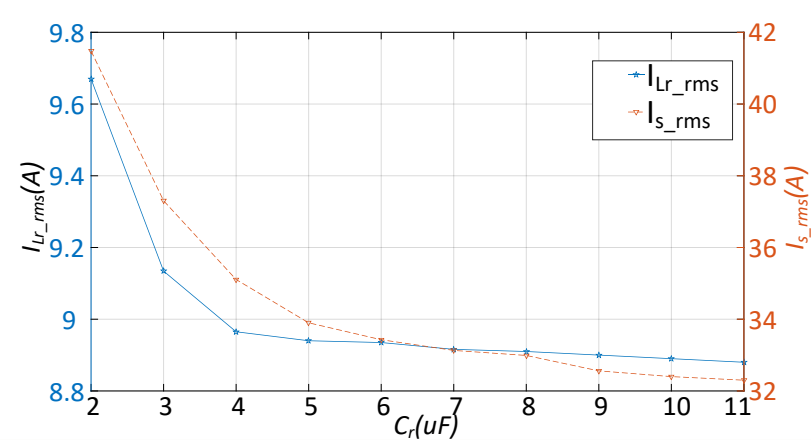

Fig.8. Primary and secondary RMS current as functions of the resonant capacitor $C_{r}$

\section{EXPERIMENT}

The circuit parameters are documented in TABLE III. The magnetic core is ER 18/3.2/10 from Hitachi. A larger resonant capacitor is selected to reduce the primary and secondary RMS current. Fig.9 shows the top view and bottom view of the prototype. It satisfies the standard $1 / 16$ brick size and achieves the power density of $468 \mathrm{~W} /$ inch $^{3}$. Two SRs are connected in parallel to share the high current. As mentioned in the previous section, the winding layout show in Case III, an 8-layer PCB, is selected for the planar transformer design. However, this prototype is only built with two 4-layer PCBs to reduce the cost. The detailed configuration is shown in Fig.10. One $S R$ is placed on the PCB together with other primary devices. The other $S R$ is located on the other PCB which only has planar windings and gate drivers. These two PCBs are soldered together to have the parallel connections of the secondary windings, $S R s$ and the series connections of the primary windings. Although the spacing between PCB 1 and PCB2 is normally larger than the insulation between each conduction, it does not affect the parallel current distribution.

TABLE III

CIRCUIT PARAMETERS

\begin{tabular}{ll}
\hline \hline Circuit parameters & Value \\
\hline$Q_{1} \sim Q_{2}$ & BSZ075N08NS5 \\
$S R$ & BSC009NE2LS5 \\
Magnetizing inductance $L_{m}$ & $2.2 \mathrm{uH}$ \\
Leakage inductance $L_{r}$ & $53 \mathrm{nH}$ \\
Resonant capacitance $C_{r}$ & $3.3 \mathrm{uF}$ \\
Turn ratio & $4: 1$ \\
Magnetic core & ER18/3.2/10 ML91S \\
\hline \hline
\end{tabular}

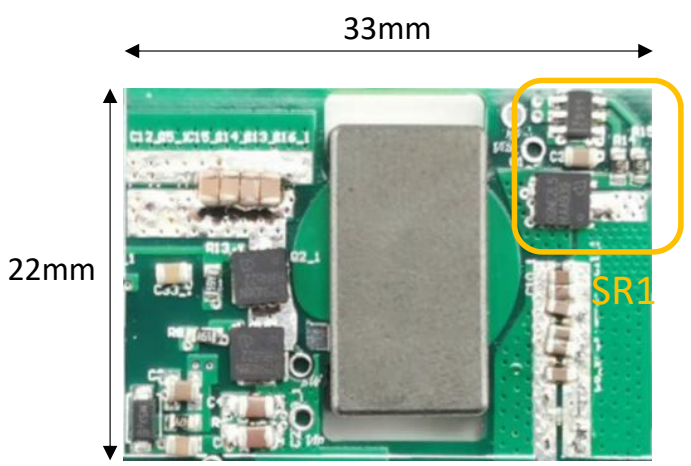

(a)

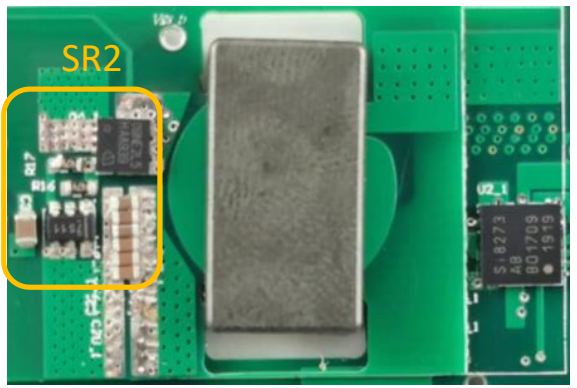

(b)

Fig.9. Top view and bottom view of the prototype

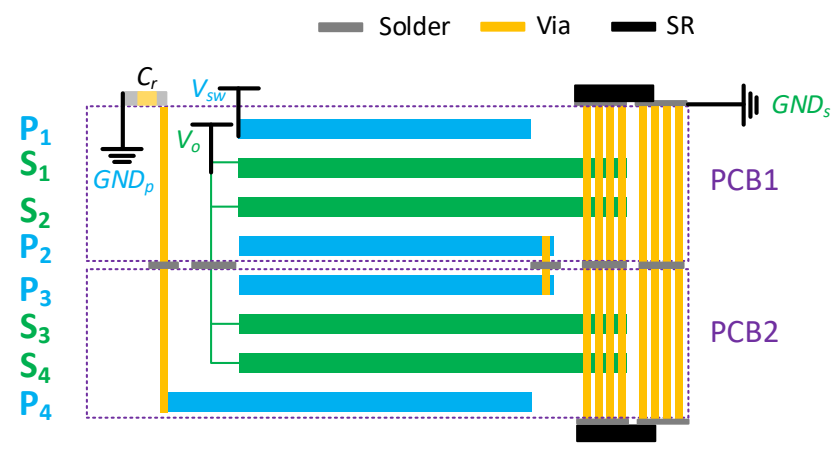

Fig.10. Planar windings configuration

Fig. 11 shows experiment waveforms at full load. ZVS is realized at different input voltages. Fig. 12 presents efficiency curves. The peak efficiency of $94.9 \%$ is realized at $36 \mathrm{~V}$. At the nominal input $48 \mathrm{~V}$, the peak efficiency is $94.8 \%$ at $60 \mathrm{~W}$. The efficiency drops to $92.7 \%$ at $100 \mathrm{~W}$. At $75 \mathrm{~V}$, the peak efficiency is $93.3 \%$.

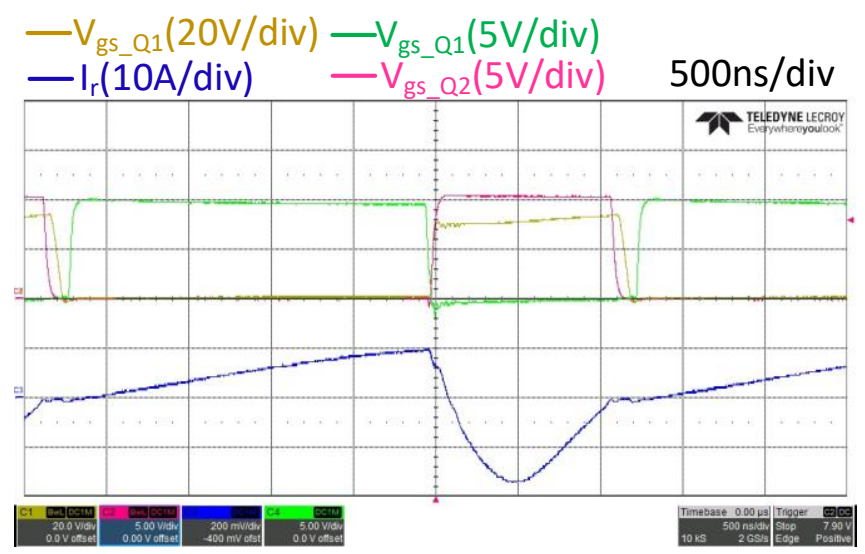

(a)

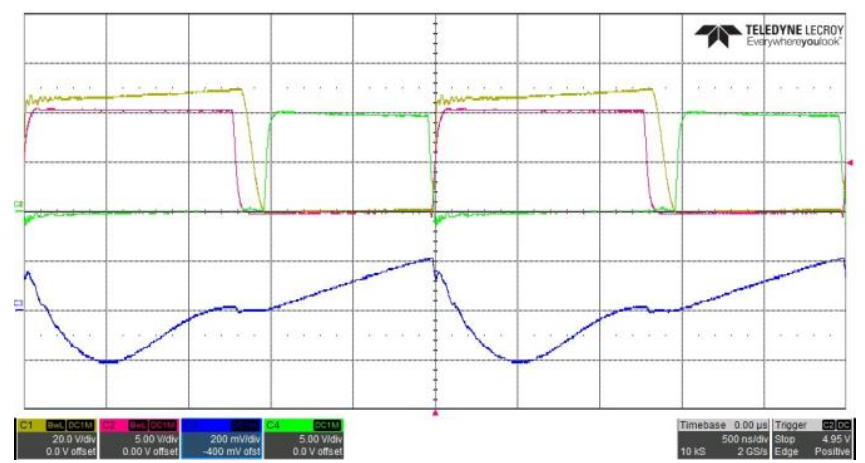

(b) 


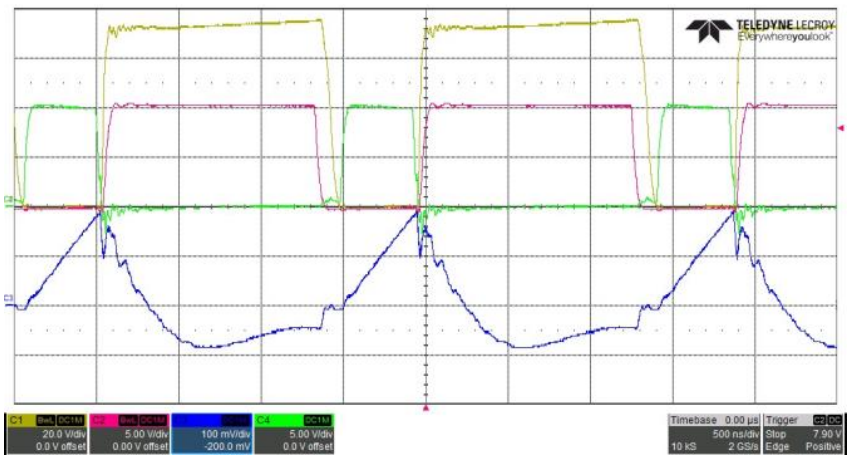

(c)

Fig.11. Experiment waveforms at (a) $36 \mathrm{~V}$, (b) $48 \mathrm{~V}$ and (c) $75 \mathrm{~V}$ full load

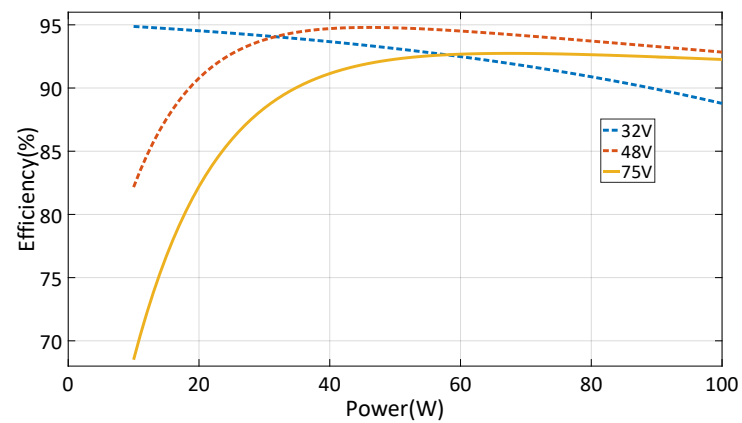

Fig.12. Efficiency curves at $32 \mathrm{~V}, 48 \mathrm{~V}$ and $75 \mathrm{~V}$

The comparison with the state-of-the-art is presented in TABLE IV. The built prototype achieves both the highest efficiency and power density.

TABLE IV

COMPARISON WITH THE STATE-OF-THE-ART

\begin{tabular}{ccccc}
\hline \hline & Input & Output & $\begin{array}{c}\text { Peak } \\
\text { efficiency }\end{array}$ & $\begin{array}{c}\text { Power } \\
\text { density } \\
\text { (W/inch3) }\end{array}$ \\
\hline V48SC05020 & $36-75 \mathrm{~V}$ & $5 \mathrm{~V} / 20 \mathrm{~A}$ & $91 \%$ & 229 \\
MYBEB00520AZT & $36-75 \mathrm{~V}$ & $5 \mathrm{~V} / 20 \mathrm{~A}$ & $\begin{array}{c}93 \% \text { at } \\
\mathrm{V} \text { in }=48 \mathrm{~V}\end{array}$ & 136 \\
PKU4105CPI & $36-75 \mathrm{~V}$ & $5 \mathrm{~V} / 20 \mathrm{~A}$ & $\begin{array}{l}93.6 \% \text { at } \\
\mathrm{V}_{\text {in }}=48 \mathrm{~V}\end{array}$ & 256 \\
AHB flyback & $32-75 \mathrm{~V}$ & $5 \mathrm{~V} / 20 \mathrm{~A}$ & $\begin{array}{l}94.8 \% \text { at } \\
\mathrm{V}_{\text {in }}=48 \mathrm{~V}\end{array}$ & 468 \\
\hline \hline
\end{tabular}

\section{CONCLUSION}

This paper presents the operating principle and design considerations of the asymmetrical half-bridge (AHB) flyback converter. The impact of the resonant capacitor is analyzed. A larger resonant capacitor tends to induce larger turn-off losses but lower primary and secondary RMS current. This converter also benefits from the interleaving winding layout. A 4:1 interleaving winding structure with balanced current distributions on secondary parallel conductors is selected. The prototype achieves $94.9 \%$ peak efficiency and $468 \mathrm{~W} /$ inch $^{3}$ power density.

\section{REFERENCES}

[1] M. Fu, C. Fei, Y. Yang, Q, Li, F. C. Li. "A Two-Stage Rail Grade DC/DC Converter Based on GaN Device." in Proc. IEEE Appl. Power Electron. Conf. and Expo., 2019

[2] C. Fei, M. H. Ahmed, F. C. Lee, Q. Li, "Two-stage 48V-12V/6V-1.8V Voltage Regulator Module with Dynamic Bus Voltage Control for Light Load Efficiency Improvement," in IEEE Transactions on Power Electronics, vol.32, no.7, pp.5628-5636

[3] Y. Ren, M. Xu, K. Yao, and F. Lee, "Two-stage 48 V power pod exploration for 64-bit microprocessor," in Proc. IEEE Appl. Power Electron. Conf. and Expo., Miami Beach, USA, 9-13 Feb.2003

[4] M. H. Ahmed, F. C. Lee, Q. Li, "High-Efficiency High-PowerDensity 48/1V Sigma Converter Voltage Regulator Module.” in Proc. IEEE Appl. Power Electron. Conf. and Expo., 2017.

[5] M. Li, Z. Ouyang and M. A. E. Andersen, "A Hybrid Multitrack-Sigma Converter with Integrated Transformer for Wide Input Voltage Regulation," 2020 IEEE Applied Power Electronics Conference and Exposition (APEC), 2020, pp. 1844-1850,2020

[6] Z. Ye, Y. Lei, and R. C. N. Pilawa-podgurski, "A 48-to-12 V Cascaded Resonant Switched-Capacitor Converter for Data Centers with 99 \% Peak Efficiency and 2500 W / in 3 Power Density," 2019 IEEE Appl. Power Electron. Conf. Expo., pp. 13-18, 2019.

[7] S. Jiang, S. Saggini, C. Nan, X. Li, C. Chung, and M. Yazdani, "Switched Tank Converters," IEEE Trans. Power Electron., vol. 34, no. 6, pp. 5048-5062, 2019.

[8] Y. Li, X. Lyu, D. Cao, S. Jiang, and C. Nan, "A 98.55\% Efficiency Switched-Tank Converter for Data Center Application," IEEE Trans. Ind. Appl., vol. PP, no. c, p. 1, 2018.

[9] Y. Wei, Q. Luo and A. Mantooth, "Hybrid Control Strategy for LLC Converter With Reduced Switching Frequency Range and Circulating Current for Hold-Up Time Operation," in IEEE Transactions on Power Electronics, vol. 36, no. 8, pp. 8600-8606, Aug. 2021.

[10] Y. Cai, M. H. Ahmed, Q. Li and F. C. Lee, "Optimal Design of Megahertz LLC Converter for 48-V Bus Converter Application," in IEEE Journal of Emerging and Selected Topics in Power Electronics, vol. 8, no. 1, pp. 495-505, March 2020.

[11] M. Li, Z. Ouyang and M.A.E. Andersen, "High-Frequency LLC Resonant Converter With Magnetic Shunt Integrated Planar Transformer" IEEE Transactions on Power Electronics, vol. 34, no. 3, 2017, pp. 2405-2415

[12] M. Li, Z. Ouyang and M.A.E. Andersen,'Analysis and Optimal Design of High Frequency and High Efficiency Asymmetrical Half-Bridge Flyback Converters', IEEE Transactions on Industrial Electronics, vol. 67 , no. 10 , pp. $8312-8321$. 